\title{
Downregulation in GATA4 and Downstream Structural and Contractile Genes in the db/db Mouse Heart
}

\author{
Tom L. Broderick,, ${ }^{1}$ Marek Jankowski, ${ }^{2}$ Donghao Wang, ${ }^{2}$ Bogdan A. Danalache, ${ }^{2}$ \\ Cassandra R. Parrott, ${ }^{1}$ and Jolanta Gutkowska ${ }^{2}$ \\ ${ }^{1}$ Laboratory of Diabetes and Exercise Metabolism, Department of Physiology, Midwestern University, 19555 North 59th Avenue, \\ Glendale, AZ, 85308, USA \\ ${ }^{2}$ Laboratory of Cardiovascular Biochemistry, Centre Hospitalier de L'Université de Montréal-Hôtel-Dieu, 3850 St-Urbaiw Street, \\ Montreal, QC, Canada H2W 1 T8
}

Correspondence should be addressed to Tom L. Broderick, tbrode@midwestern.edu

Received 13 December 2011; Accepted 2 January 2012

Academic Editors: C. Fürnsinn, V. Saengsirisuwan, and Y. Tajiri

Copyright ( $) 2012$ Tom L. Broderick et al. This is an open access article distributed under the Creative Commons Attribution License, which permits unrestricted use, distribution, and reproduction in any medium, provided the original work is properly cited.

\begin{abstract}
Reduced expression of GATA4, a transcriptional factor for structural and cardioprotective genes, has been proposed as a factor contributing to the development of cardiomyopathy. We investigated whether the reduction of cardiac GATA4 expression reported in diabetes alters the expression of downstream genes, namely, atrial natriuretic peptide (ANP), B-type natriuretic, peptide (BNP), and $\alpha$ - and $\beta$-myosin heavy chain (MHC). db/db mice, a model of type 2 diabetes, with lean littermates serving as controls, were studied. $\mathrm{db} / \mathrm{db}$ mice exhibited obesity, hyperglycemia, and reduced protein expression of cardiac GLUT4 and IRAP (insulinregulated aminopeptidase), the structural protein cosecreted with GLUT4. Hearts from $\mathrm{db} / \mathrm{db}$ mice had reduced protein expression of GATA4 $(\sim 35 \%)$ with accompanying reductions in mRNA expression of ANP $(\sim 40 \%)$, BNP $(\sim 85 \%)$, and $\alpha$-MHC mRNA $(\sim 50 \%)$ whereas expression of $\beta$-MHC mRNA was increased by $\sim 60 \%$. Low GATA 4 was not explained by an increased ligase or atrogin 1 expression. CHIP protein content was modestly downregulated $(27 \%) \mathrm{in} \mathrm{db} / \mathrm{db}$ mice whereas mRNA and protein expression of the CHIP cochaperone HSP70 was significantly decreased in db/db hearts. Our results indicate that low GATA4 in $\mathrm{db} / \mathrm{db}$ mouse heart is accompanied by reduced expression of GATA4-regulated cardioprotective and structural genes, which may explain the development of cardiomyopathy in diabetes.
\end{abstract}

\section{Introduction}

Diabetes is a major risk factor in the development of cardiovascular disease [1]. Impairment of left ventricular function is frequent in patients with type 2 diabetes even in the absence of ischemic, hypertensive, and valvular heart disease $[2,3]$. Type 2 diabetes is associated with increased adverse outcomes following ischemic events, reflected by a heightened mortality rate [4]. Although disturbances in energy metabolism and vascular endothelial function play a role in the development of left ventricular dysfunction, altered transcription of genes encoding for contractile and structural proteins also contribute to the cardiovascular risk of diabetic patients [5-8].

GATA4 is a zinc finger-containing transcription factor that belongs to the GATA superfamily [9]. GATA4 is highly expressed in cardiomyocytes where it regulates the transcription of $\alpha$ - and $\beta$-myosin heavy chain (MHC) composition, atrial natriuretic (ANP), and B-type natriuretic (BNP) peptides, which are important in cardiac function, blood pressure regulation, and cardioprotection $[9,10]$. Accordingly, GATA4 is essential for important adaptive responses such as cardiomyocyte survival, hypertrophy in response to pressure overload and exercise, and protection against ischemic insult [11-14]. In failing rat hearts, GATA4 levels are markedly reduced and recent evidence indicates that cardiac GATA4 degradation is increased in diabetes $[15,16]$.

In hearts from diabetic $\mathrm{db} / \mathrm{db}$ mice, low levels of GATA4 are thought to occur as a result of increased E3 ubiquitin ligase carboxyl terminus of Hsp70-interacting protein (CHIP) activity [16]. Alternatively, a recent study 
demonstrated the importance of CHIP and its cochaperone heat shock protein 70 (HSP70), in the critical rescue of the myocardium from acute ischemia. In mouse hearts from CHIP-deleted mice, HSP levels are correspondingly low, and an increased susceptibility to ischemic injury is observed as left ventricular function is compromised [17]. Based on this evidence, low GATA4 levels in the $\mathrm{db} / \mathrm{db}$ heart would suggest that the documented cardiomyopathy in this model of diabetes may be accompanied by a downregulation of GATA4-regulated structural and cardioprotective genes.

Stimulation of the oxytocin receptor is a key component of a cardioprotective system associated with ANP, BNP, and nitric oxide synthesis, and stimulation of glucose uptake [1821]. Considering the role of GATA4 in the regulation of these natriuretic peptides and contractile proteins, a reduction in cardiac GATA4 would suggest that the synthesis of these genes is altered by the diabetic state. Thus, in the present study, we hypothesize that hearts from $\mathrm{db} / \mathrm{db}$ mice exhibit specific disturbances in the expression of structural and cardioprotective genes resulting from low GATA4 levels. To test this hypothesis, we used the $\mathrm{db} / \mathrm{db}$ mouse model of diabetes because of its close representation of human type 2 diabetes and also because the GATA4-regulated downstream genes in this model of diabetes have not been determined. The onset of diabetes in the $\mathrm{db} / \mathrm{db}$ mouse is gradual and is characterized by obesity, hyperglycemia, hyperinsulinemia, and insulin resistance and by 12-16 weeks of age, hearts demonstrate increased susceptibility to ischemic injury, cardiomyopathy from increased fibrosis, collagen accumulation and increased apoptosis, and left ventricular dysfunction [22-24].

\section{Materials and Methods}

2.1. Mouse Model of Diabetes. The Midwestern University Research and Animal Care Committee approved this study. All animals used in this study were cared, in accordance to the recommendations in The Guide for the Care and Use of Laboratory Animals, National Institute of Health, Publ. No. 85-23, 1986. Diabetic mice (C57BL/KsJ-lept ${ }^{\mathrm{db}}-$ lept $^{\mathrm{db}}$ ) were obtained from Jackson Laboratories (Bar Harbor, ME) and studied at the age of 14 weeks. The $\mathrm{db} / \mathrm{db}$ mouse displays many of the metabolic perturbations associated with type 2 diabetes as a result of two mutant copies of the leptin receptor gene. The lean littermates, which possess one mutant and one normal copy of the leptin $\left(\mathrm{db} /{ }^{+}\right)$, were used as controls. Mice were provided with food and water were provided ad libitum and maintained in a room with alternating twelvehour light/dark cycle and kept at $22^{\circ} \mathrm{C}$.

2.2. Measurement of Blood Pressure. Systolic and diastolic pressures were measured from restrained mice with a pneumatic tail-cuff device (NIBP-8, Columbus instruments, Columbus, $\mathrm{OH}$ ). From these measurements, mean arterial pressure (MAP) and heart rate were determined. Blood pressure readings were obtained two days before the mice were sacrificed.
2.3. Blood and Tissue Sampling. Overnight-fasted mice were sacrificed in the morning between 8 and 11 AM. Blood was obtained from the mandibular vein, and then mice were immediately sacrificed by cervical dislocation. Blood was immediately centrifuged $\left(3,000 \mathrm{rpm}\right.$ at $4^{\circ} \mathrm{C}$, for $5 \mathrm{~min}$ ) and plasma separated from the erythrocytes for the assay of glucose (Wako Chemical, VA). The packed erythrocytes were used for the determination of glycosylated haemoglobin (Helena Laboratories, TX).

Hearts were rapidly removed and frozen with clamps precooled to the temperature of liquid $\mathrm{N}_{2}$ for analysis of GATA4, ANP, BNP, $\alpha$ - and $\beta$-MHC, Nab1, heat shock protein70 (HSP70), glucose transporter protein (GLUT4), insulin-regulated aminopeptidase (IRAP), and the following E3 ubiquitin ligases: carboxyl terminus of Hsp 70-interacting protein (CHIP), muscle ring finger protein-1 (MuRF1), and atrogin 1 genes. Frozen tissue was first ground to powder under liquid nitrogen and then thoroughly homogenized using a Teflon pestle in a glass homogenization tube cooled in ice.

2.4. Cell Morphology and Imaging. Primary cardiomyocytes cultures were prepared from ventricles of 2-day-old Sprague Dawley rats using the Neonatal Cardiomyocyte Isolation System (Cat. No. LK003300; Worthington, Lakewood, NJ) as reported previously [20]. The cells were incubated $24 \mathrm{~h}$ in $0.01 \%$ poly-LlLysine (Cat. no. P4832-covered Lab-Tek plates, Sigma-Aldrich; Cat. no. 177437, Nunc International, Rochester, NY) for microscopic analysis. Tissuefix solution (Laboratory Gilles Chaput Inc., Montreal, Quebec) was used for cell fixation. Primary anti- GATA-4 (c-20) goat antibody (Cat. no. sc-1237, Santa Cruz Biotechnology, Santa Cruz, CA) was used at $1: 250$ dilution. Secondary donkey anti-goat IgG secondary antibody conjugated to red fluorophore Alexa Fluor 594 was obtained from Invitrogen (Cat. no. A11058, Life Technologies, Carlsbad, CA). GATA4 was costained with troponin $\mathrm{C}$ using mouse monoclonal antibody against cardiac troponin (1:100, Cat. no. ab7217-7, Abcam, Cambridge, MA). Green secondary donkey anti-mouse IgG antibody Alexa Fluor 488 was purchased from Invitrogen (Cat. no. A21202, Life Technologies, Carlsbad, CA). Mounting medium DAPI (4',6-diamidino-2-phenylindole) with P7481 antifade reagent (Invitrogen, Cat. No. P7481, Life Technologies, Carlsbad, CA) was used for the identification of the nuclei. Cell morphology was examined under a Model IX51 inverted microscope (Olympus, Tokyo, Japan). Micrographs were taken with a Q Imaging QICAM-IR Fast 1394 Digital CCD camera. To measure cardiomyocyte size, the surface of 50 cells was recorded manually using at least 7 photographs and then calculated in $\mu \mathrm{m}^{2}$. Micrographs and cardiomyocyte cell size were analyzed using Image J software (National Institutes of Health, Bethesda, MD).

2.5. Real-Time PCR. Total RNA was extracted from freezeclamped hearts with Trizol reagent (Invitrogen Life Technologies, Burlington, ON) according to the manufacturer's protocol. To remove genomic DNA, RNA samples were incubated with 2 U deoxyribonuclease I (DNase I; Invitrogen 
TABLE 1: PCR primer sequences.

\begin{tabular}{llll}
\hline Gene & Sense primer $\left(5^{\prime}-3^{\prime}\right)$ & Antisense primer $\left(5^{\prime}-3^{\prime}\right)$ & Accession no. \\
\hline ANP & CCTGTGTACAGTGCGGTGTC & CCTAGAAGCACTGCCGTCTC & NM_008725 \\
BNP & CTGAAGGTGCTGTCCCAGAT & GTTCTTTTGTGAGGCCTTGG & NM_008726 \\
IRAP & CAAAGACCGAGCCAACCTGATC & GCTAAAGAGGAACAACCAGCC & NM_172827 \\
GATA & CACTATGGGCACAGCAGCTCC & TTGGAGCTGGCCTGCGATGTC & NM_008092 \\
$\alpha$-MHC & CTGCTGGAGAGGTTATTCCTCG & GGAAGAGTGAGCGGCGCATCAAGG & NM_001164171 \\
$\beta$-MHC & TGCAAAGGCTCCAGGTCTGAGGGC & GCCAACACCAACCTGTCCAAGTTC & NM_080728 \\
CHIP & AGGGCAAGGAGGAAAAGGA & TGGCAATGGCCTCATCATAA & NM_019719 \\
Atrogin 1 & ACTGGACTTCTCGACTGCCAT & CTCCATCCGATACACCCACAT & AF441120 \\
MURF1 1 & AACACAACCTCTGCCGGAA & AGCCCCAAACACCTTGCA & DQ229108 \\
GLUT4 & ACCCTGGGCTCTGTATCCC & CCCTGACCACTGAGTGCAAA & AB008453 \\
NAB1 & TGCTGACAAGAAGAGATGAG & TCCTGGTTTCCACAGACTAC & NM_008667 \\
GAPDH & TTCACCACCATGGAGAAGGC & GGCATGGACTGTGGTCATGA & NM_008084 \\
\hline
\end{tabular}

ANP: atrial natriuretic peptide; BNP: brain natriuretic peptide; IRAP: insulin-regulated aminopeptidase; G4: GATA binding protein 4; $\alpha$-MHC: alpha-myosin heavy chain; $\alpha$-MHC: beta-myosin heavy chain; CHIP: carboxy terminus of Hsc70-interacting protein; atrogin1: F-box protein 32; MuRF1: muscle RING finger protein 1; GLUT4: glucose transporter protein 4; NAB1: NGF1A-binding protein; GAPDH: glyceraldehyde-3-phosphate dehydrogenase.

Life Technologies, Burlington, ON)/ $\mu \mathrm{g}$ RNA for $30 \mathrm{~min}$ at $37^{\circ} \mathrm{C}$. PCR was carried out in the iCycler IQ real-time PCR detection system (Bio-Rad Laboratories, Hercules, CA) using SYBR green chemistry. The samples were analysed in duplicate or triplicate. For amplification, $2 \mu \mathrm{L}$ of diluted cDNA were added to a $20 \mu \mathrm{L}$ reaction mixture containing $1 \mathrm{X}$ iQ SYBR Green Supermix (Bio-Rad Laboratories, Hercules, $\mathrm{CA}$ ) and $200 \mathrm{nM}$ forward and reverse primers. The thermal cycling program was $95^{\circ} \mathrm{C}$ for $2 \mathrm{~min}$, followed by 40 cycles of $95^{\circ} \mathrm{C}$ for $25 \mathrm{~s}, 60^{\circ} \mathrm{C}$ for $25 \mathrm{~s}$, and $72^{\circ} \mathrm{C}$ for $25 \mathrm{~s}$. The primers were purchased from Invitrogen Life Technologies (Burlington, ON). Primer sets served to generate amplicons (Table 1). Optical data were recorded during the annealing step of each cycle. After PCR, the reaction products were melted for $1 \mathrm{~min}$ at $95^{\circ} \mathrm{C}$, the temperature was lowered to $55^{\circ} \mathrm{C}$, and then gradually increased to $95^{\circ} \mathrm{C}$ in $1.0^{\circ} \mathrm{C}$ increments, $10 \mathrm{~s}$ per increment. Optical data were collected over the duration of the temperature increments, with a dramatic drop in fluorescence occurring. This was done to ensure that only 1 PCR product was amplified per reaction.

The relative expression of the RT-PCR products was determined by the $\Delta \Delta \mathrm{Ct}$ method. This method calculates relative expression using the equation: fold induction $=$ $2^{-[\Delta \Delta \mathrm{Ct}]}$, where $\mathrm{Ct}=$ the threshold cycle, that is, the cycle number at which the sample's relative fluorescence rises above background fluorescence and $\Delta \Delta \mathrm{Ct}=[\mathrm{Ct}$ gene of interest (unknown sample)-Ct GAPDH (unknown sample)]-[Ct gene of interest (calibrator sample)-Ct GAPDH (calibrator sample)]. One of the control samples was chosen as the calibrator sample and tested in each PCR. Each sample was run in duplicate, and mean $\mathrm{Ct}$ was taken in the $\Delta \Delta \mathrm{Ct}$ equation. GAPDH was chosen for normalization because this gene showed consistent expression relative to other housekeeping genes among the treatment groups in our array experiments.

2.6. Western Blot Analysis. Heart samples $(\sim 100 \mathrm{mg})$ were prepared by homogenisation in modified RIPA buffer
( $1 \times$ PBS, $1 \%$ Igepal CA-630, $0.5 \%$ sodium deoxycholate, $0.1 \%$ SDS, $10 \mathrm{mg} / \mathrm{mL}$ PMSF, aprotinin, $100 \mathrm{mM}$ sodium orthovanadate and $4 \%$ protease inhibitor). After 2 hours in constant agitation at $4^{\circ} \mathrm{C}$, the samples were centrifuged at $10,000 \mathrm{~g}$ for $20 \mathrm{~min}$ at $4^{\circ} \mathrm{C}$. The supernatants were collected and the protein concentration was determined by a modified Bradford assay. Thirty micrograms of total protein were applied to each well of $10 \%$ SDS polyacrylamide gel and electrophoresed for $2 \mathrm{~h}$ at $130 \mathrm{~V}$ (MHC: $20 \mathrm{~h}$ at $140 \mathrm{v}$ ) along with a set of molecular weight markers (RPN800, Amersham Biosciences, Baie dUrfe, PQ). The resolved protein bands were then transferred onto PVDF membranes (Hybond-C; Amersham Pharmacia Biotech Inc., Piscataway, $\mathrm{NJ}$ ) at $20 \mathrm{~V}$ for $60 \mathrm{~min}$ at room temperature using a transfer buffer $(25 \mathrm{mmol} / \mathrm{L}$ Tris base, $192 \mathrm{mmol} / \mathrm{L}$ glycine, and $20 \%$ methanol). The blots were blocked overnight at $4{ }^{\circ} \mathrm{C}$ with blocking buffer consisting of 5\% nonfat milk in $10 \mathrm{mmol} / \mathrm{L}$ Tris $\mathrm{pH} 7.5,100 \mathrm{mmol} / \mathrm{L} \mathrm{NaCl}, 0.1 \%$ Tween 20 (Amersham Pharmacia Biotech Inc, Piscataway, NJ). The membranes were then probed with specific primary antibodies: GATA4 (1:500, sc-25310, Santa Cruz Biotechnology, Santa Cruz, CA), Nab1 (1:1000, sc-12147, Santa Cruz Biotechnology), HSP70 (1:10,000, sc-32239, Santa Cruz Biotechnology), CHIP (1:2000, sc-133083, Santa Cruz Biotechnology), GLUT4 (1:10000, 4670-1725, AbD), IRAP $(1: 10000$, kindly given by Dr. Pilch, Boston University School of Medicine, MA), MHC (1:5000, NB 300-284, Novus Biologicals, Littleton, CO) overnight at $4^{\circ} \mathrm{C}$. As an internal control, blots were reprobed with an anti- $\beta$-GAPDH antibody (1:20000; G9545-200UL, Sigma-Aldrich). Blots were then washed using TBS washing buffer $(10 \mathrm{mmol} / \mathrm{L}$ Tris $\mathrm{pH} 7.5,100 \mathrm{mmol} / \mathrm{L} \mathrm{NaCl}, 0.1 \%$ Tween 20 ) and incubated with horseradish peroxidase-conjugated immunoglobulin G (IgG) (anti-mouse for GATA4, GLUT4, HSP70, and MHC, $1: 10000$; anti-goat for Nab1, $1: 10000$; anti-rabbit for IRAP and GAPDH, $1: 10000$ ) during $1 \mathrm{~h}$ at room temperature. The blots finally were detected by chemiluminescence detection system (RPN2132, Amersham Biosciences, Baie dUrfe, PQ) 


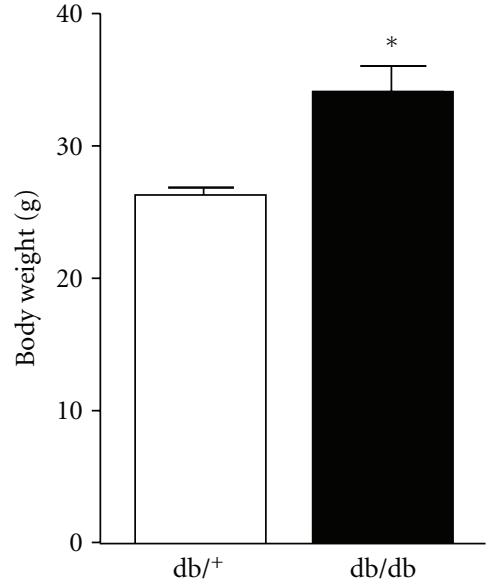

(a)

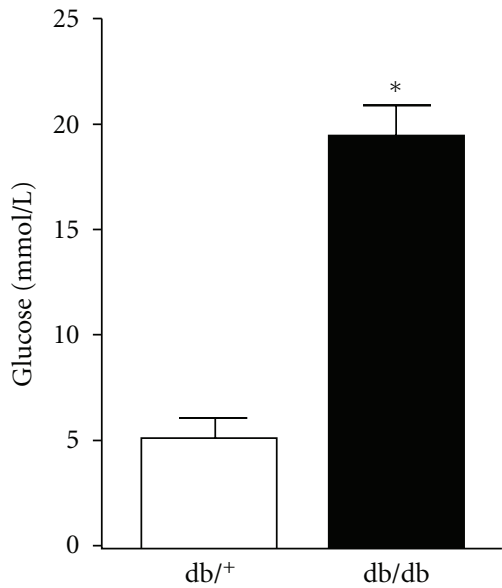

(b)

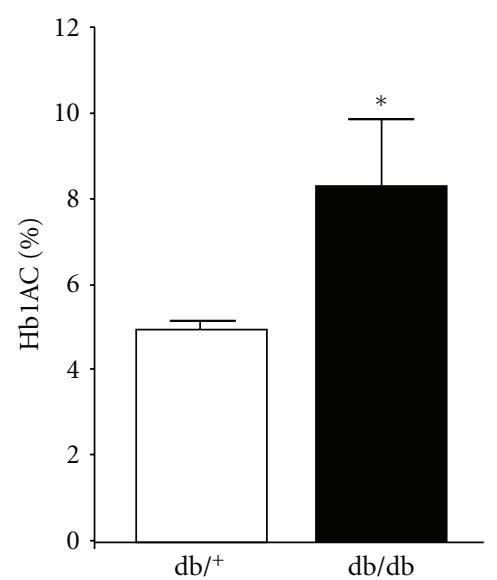

(c)

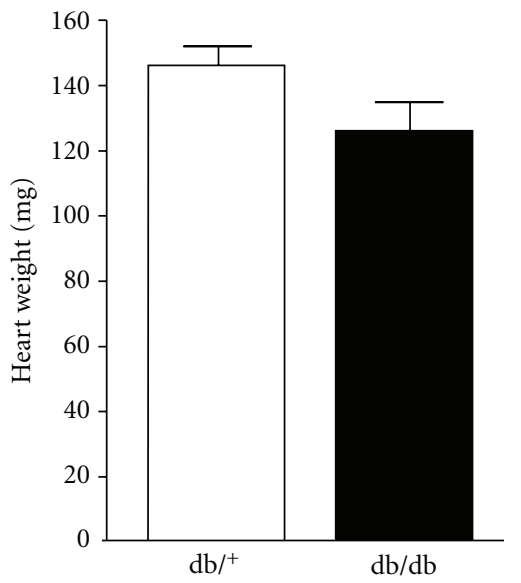

(d)

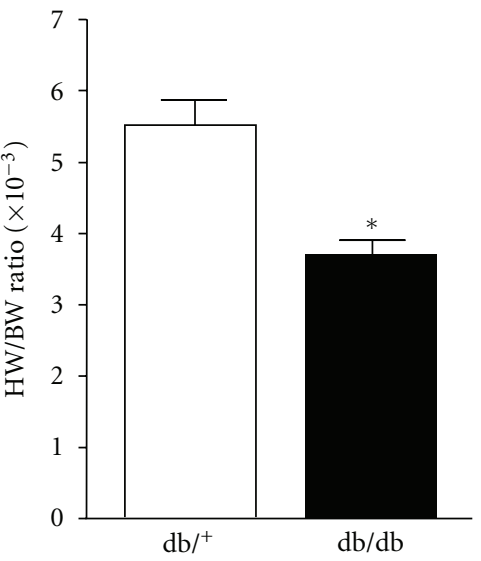

(e)

FIGURE 1: Body weight (a), plasma glucose (b), glycated haemoglobin (c), heart weight (d), and the heart-weight-to-body-weight ratio (e) in control and $\mathrm{db} / \mathrm{db}$ mice. Values are expressed as mean \pm SEM for $10-12$ mice in each group. $\mathrm{db} /{ }^{+}$, control mice; $\mathrm{db} / \mathrm{db}$, diabetic mice. $* P<0.05$.

and visualized by exposure to Kodak X-Omat film. Densitometric measurement of the bands was performed using Photoshop 7 software.

2.7. Statistical Analysis. The statistical analysis was performed using the statistical software package Prism 3.0. The unpaired $t$-test was used to determine differences between group means. All values are expressed as mean \pm SEM with significance defined as $P<0.05$.

\section{Results}

3.1. Physical Characteristics, Blood Pressure, GLUT4, and IRAP Expression in $d b / d b$ Mice. The physical characteristics of $\mathrm{db} / \mathrm{db}$ mice are illustrated in Figure 1. Body weight, plasma glucose, and glycated $\left(\mathrm{Hb}_{1 \mathrm{AC}}\right)$ haemoglobin levels were all significantly higher in $\mathrm{db} / \mathrm{db}$ mice compared with control mice, confirming the typical phenotype of this model of diabetes. Although heart weight in $\mathrm{db} / \mathrm{db}$ mice was similar to compared with control mice, the heart-to-body-weight ratio was significantly lower. Also consistent with hearts from $\mathrm{db} / \mathrm{db}$ mice is a significant decrease $(40 \%, P<0.05)$ in protein expression of cardiac GLUT4 compared with control mice, as shown in Figure 2. This reduction in GLUT4 was associated with a concomitant decrease in mRNA $(60 \%, P<$ $0.01)$ and protein expression $(75 \%, P<0.001)$ of IRAP which codistributes with GLUT4.

Blood pressure obtained in control $(n=6)$ and $\mathrm{db} / \mathrm{db}$ mice $(n=5)$ demonstrated that systolic pressure was significantly higher in $\mathrm{db} / \mathrm{db}$ mice compared with control mice $(115 \pm 2$ versus $101 \pm 5 \mathrm{mmHg}, P<0.05)$. However, there were no differences in diastolic pressure ( $82 \pm 4$ versus $76 \pm 5 \mathrm{mmHg}$ ), MAP (92 \pm 5 versus $84 \pm 5 \mathrm{mmHg}$ ), and heart rate ( $475 \pm 15$ versus $499 \pm 34$ beats/min) between $\mathrm{db} / \mathrm{db}$ mice and control mice, respectively.

3.2. GATA4 and Expression of Downstream Genes in $d b / d b$ Hearts. As illustrated in Figure 3(a), GATA4 is localized in the cell nuclei. Gene expression of GATA4 was not altered in $\mathrm{db} / \mathrm{db}$ hearts (Figure 3(b)). However, a significant reduction 


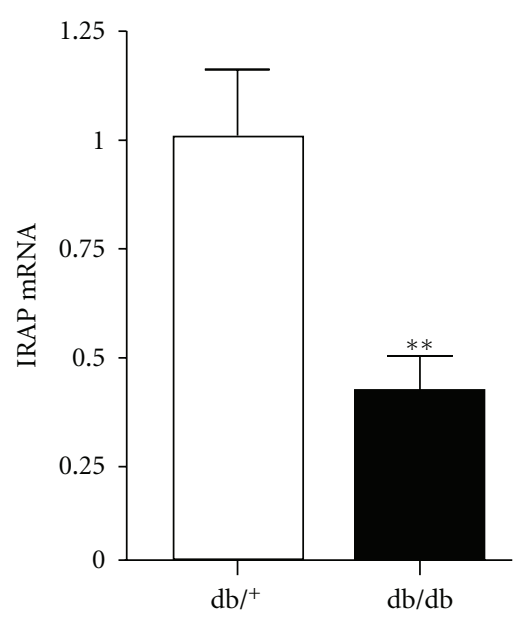

(a)

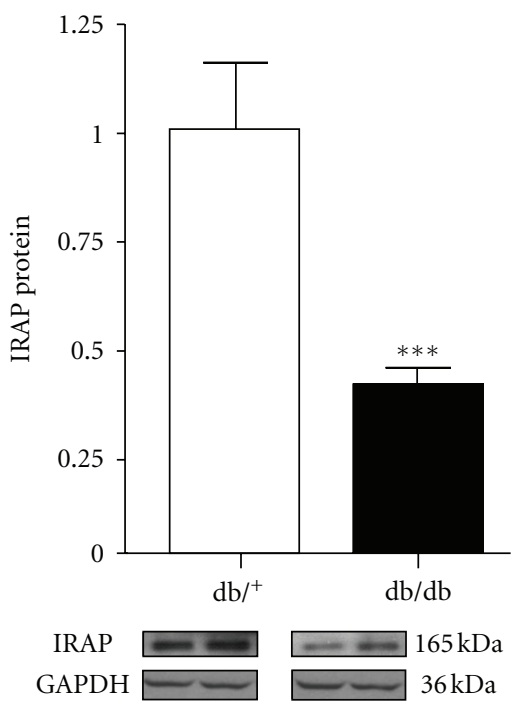

(c)

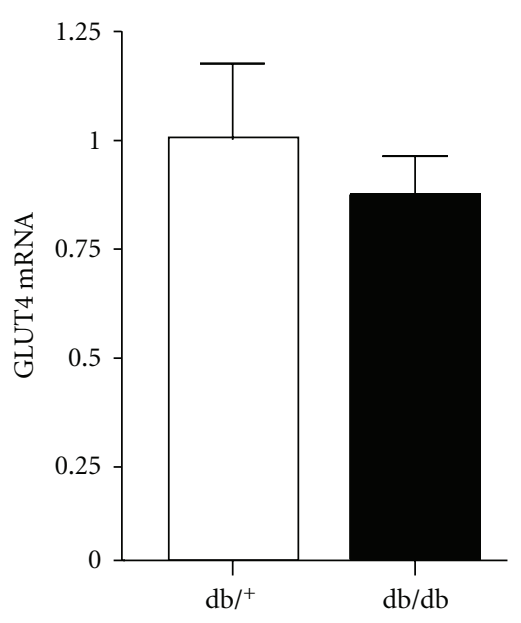

(b)

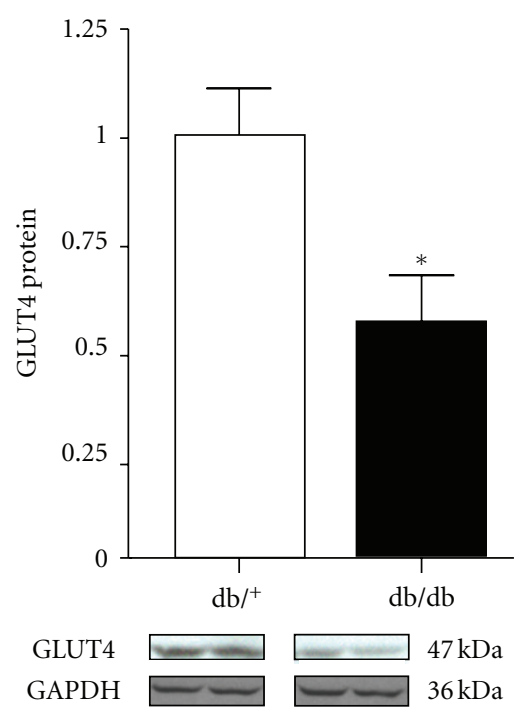

(d)

FIGURE 2: Cardiac GLUT4 and IRAP mRNA and protein expression in control and $\mathrm{db} / \mathrm{db}$ mice. Values are expressed as mean \pm SEM obtained from 2 separate experiments each performed with 5 hearts. $\mathrm{db} /{ }^{+}$, control mice; db/db, diabetic mice. ${ }^{*} P<0.05,{ }^{* *} P<0.01,{ }^{* * *} P<0.001$.

$(27 \%, P<0.05)$ in GATA4 protein expression was observed in $\mathrm{db} / \mathrm{db}$ hearts compared with control hearts (Figure $3(\mathrm{c})$ ). Figure 3(d) shows that GATA4 was present in nuclei of cells expressing the cardiomyocyte marker, troponin C. Hearts from $\mathrm{db} / \mathrm{db}$ mice showed a tendency towards a lower weight (Figure 1(d)), but cardiomyocyte enlargement was observed in these hearts (Figure 3(e2), 3(e3)) compared with control hearts (Figure 3(e1)).

The consequences of reduced cardiac GATA4 expression on downstream genes of interest are shown in Figures 4 and 5. Figure 4 shows that the reduction in GATA 4 in $d b / d b$ hearts was associated with downregulation in the mRNA expression of ANP by $40 \%(P<0.05)$ and BNP by $85 \%$ $(P<0.01)$ compared with control hearts. As illustrated in Figure 5, mRNA expression of $\alpha$-MHC in $\mathrm{db} / \mathrm{db}$ hearts was reduced by nearly 50\% $(P<0.05)$ whereas $\beta$-MHC expression was increased by $\sim 60 \%(P<0.05)$. Compared with control hearts, a significant reduction $(P<0.05)$ in protein expression of $\alpha$-MHC was observed in $\mathrm{db} / \mathrm{db}$ hearts. Protein expression of $\beta$-MHC in control hearts was not detected, which is consistent with the observation that the dominant isoform consists of mainly the $\alpha$-MHC in nondiseased hearts [25]. However, expression of $\beta$-MHC was markedly increased in $\mathrm{db} / \mathrm{db}$ hearts.

3.3. Ubiquitin Ligase CHIP, MuRF1, Atrogin1, and Nab1 Expression in $d b / d b$ Hearts. To investigate whether the decrease in GATA4 protein expression in hearts of $\mathrm{db} / \mathrm{db}$ mice was the result of increased proteosome activity, expression of ubiquitin ligases of CHIP, MuRF1, and atrogin1 were measured. As illustrated in Figure 6, no significant differences between $\mathrm{db} / \mathrm{db}$ and control hearts were observed in the expression of these ligases, although CHIP protein expression was decreased by $26 \%$ in $\mathrm{db} / \mathrm{db}$ hearts. However, we measured the molecular chaperone HSP70 because of 


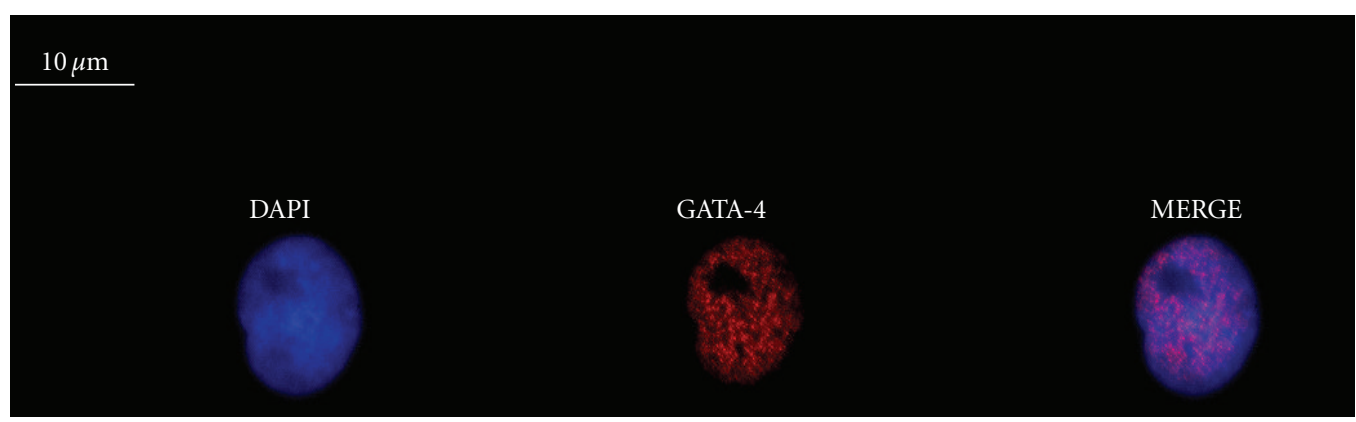

(a)
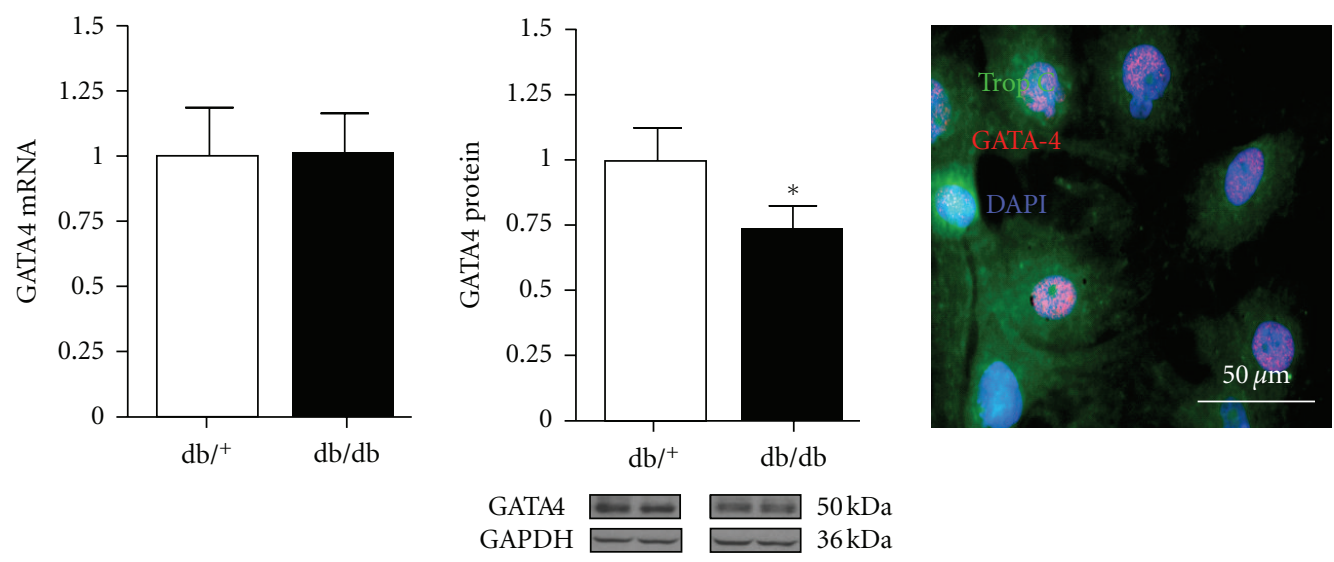

(c)

(d)

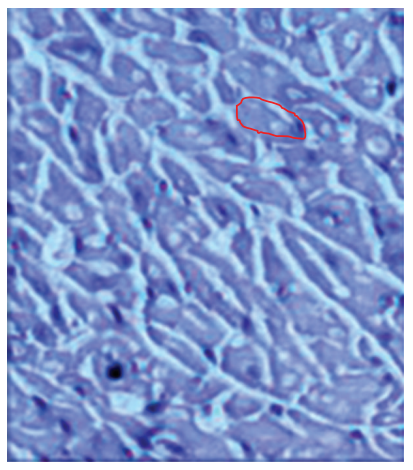

(e1)

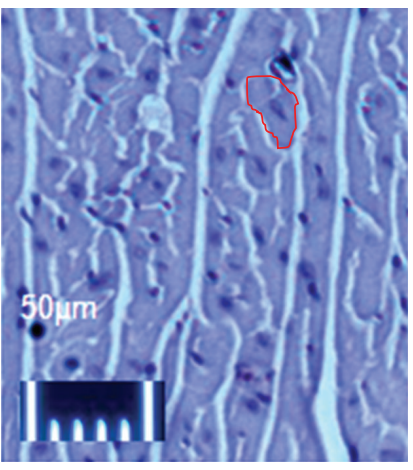

(e2)

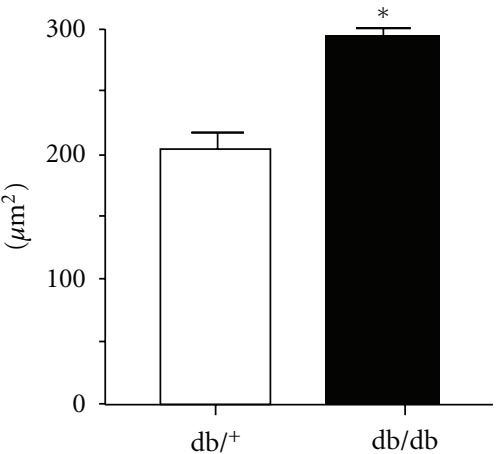

(e3)

FIGURE 3: GATA4 is localized in the cell nuclei of cardiomyocytes of 2-day-old rats (a). GATA4 mRNA is expression is similar to that seen in control hearts (b). However, as illustrated in (c), protein expression of GATA4 is downregulated in db/db hearts (c). GATA4 was present in nuclei of the cells expressing cardiomyocyte marker, troponin $\mathrm{C}(\mathrm{d})$. Hearts from $\mathrm{db} / \mathrm{db}$ mice showed a tendency toward a reduced weight (d), but cardiomyocyte surface was increased in $\mathrm{db} / \mathrm{db}$ hearts (Figure 3e2) compared with control hearts (Figure 3e1). Figure (e3) shows that cardiomyocyte surface area, expressed as $\mu \mathrm{m}^{2}$, was significantly increased in $\mathrm{db} / \mathrm{db}$ hearts compared with control hearts. Values are expressed as mean \pm SEM obtained from 2 separate experiments each performed with 5 hearts. $\mathrm{db} /{ }^{+}$, control mice; db/db, diabetic mice. ${ }^{*} P<0.05$.

its association with CHIP, and as shown in Figure 7, both HSP70 mRNA and protein expression were decreased by $45 \%$ and $35 \%$, respectively, in $\mathrm{db} / \mathrm{db}$ hearts compared with control hearts (Figure 7).

The cardiac hypertrophy marker Nab-1 was measured in $\mathrm{db} / \mathrm{db}$ hearts. Nab1 (NGF1A-binding protein) is a member of a family of corepressors for early growth response (Egr) transcription factors that interacts with the inhibitory R1 repression domain of Egr1, thus acting as an endogenous regulator of pathological cardiac growth. As shown in Figure $8, \mathrm{mRNA}$ levels were not altered in $\mathrm{db} / \mathrm{db}$ hearts. However, Nab-1 protein levels were reduced by $65 \%(P<$ $0.01)$ in $\mathrm{db} / \mathrm{db}$ hearts compared with control hearts.

\section{Discussion}

The $\mathrm{db} / \mathrm{db}$ mouse is a widely accepted model for studying the consequences of type 2 diabetes on metabolic and 


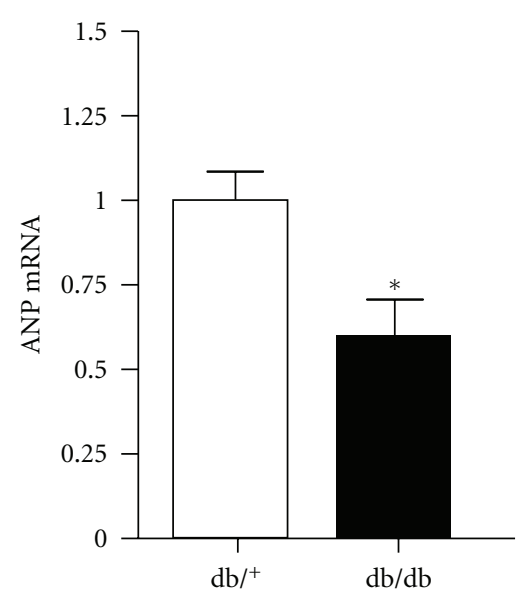

(a)

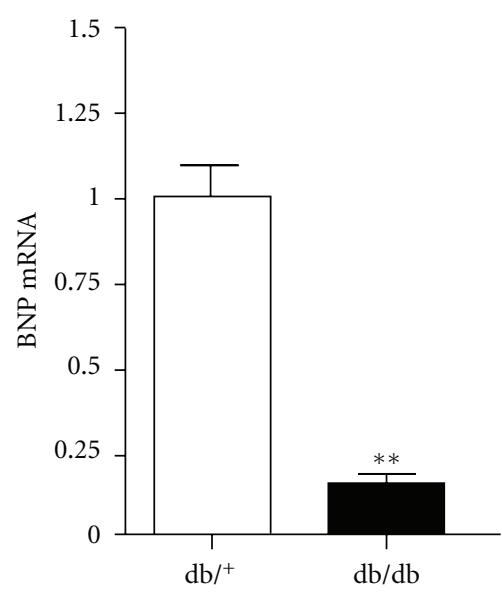

(b)

FIgure 4: Cardiac ANP and BNP mRNA expression in control and db/db mice. Values are expressed as mean \pm SEM obtained from 2 separate experiments each performed with 5 hearts. $\mathrm{db} /{ }^{+}$, control mice; $\mathrm{db} / \mathrm{db}$, diabetic mice. ${ }^{*} P<0.05,{ }^{* *} P<0.01$.

cardiovascular function because this model shares several features with the human condition. The mice used in this study were obese, chronically hyperglycemic, and were studied at an age when hearts demonstrate alterations in structure and deficiencies in ventricular performance [22, 24]. A recent study demonstrated that acute hyperglycemia and the diabetic conditions induce degradation of cardiac GATA4 [16], an abundant transcription factor in heart that functions mainly as regulator of ANP, BNP, and $\alpha$ and $\beta$-MHC expression $[9,10]$. However, the consequences of reduced cardiac GATA4 levels on expression of these structural genes and peptides in the $\mathrm{db} / \mathrm{db}$ model of type 2 diabetes have not been determined. Our main results demonstrate that the low GATA4 protein levels in $\mathrm{db} / \mathrm{db}$ hearts validate its regulatory role on the mRNA expression of ANP, BNP, and $\alpha-\mathrm{MHC}$, indicating that these changes in target gene expression are consistent with the transcriptional role of GATA4. One exception, however, is that $\beta$-MHC expression was increased in $\mathrm{db} / \mathrm{db}$ hearts. Further, we show that decreased GATA4 levels in $\mathrm{db} / \mathrm{db}$ hearts are not caused by increased E3-ubiquitin proteosome function using the ligases MuRF1, atrogin1, and CHIP as markers. On the other hand, a significant decrease in CHIP molecular cochaperone HSP70 was observed in $\mathrm{db} / \mathrm{db}$ hearts.

It is unclear why GATA4 protein levels are low in the $\mathrm{db} / \mathrm{db}$ heart and what the mechanisms involved in this response are. Hyperglycemia per se has been previously proposed as a mechanism depleting cardiac GATA4 [16]. In conditions acutely mimicking the diabetic state with hyperglycemia or with chronic diabetes, degradation of cardiac GATA4 levels is accelerated. This degradation is thought to be mediated by ubiquitination through increased expression of the ubiquitin proteasome system $[16,26]$. In agreement with this mechanism and also proposed to be a contributing factor to the development of cardiomyopathy, hyperglycemia upregulates the expression of E3-ubiquitin ligase CHIP resulting in GATA4 protein degradation. In our study, however, low levels of GATA4 were not associated with any significant increases in the expression of CHIP as previously reported, or in the expression of the ligases MuRF-1 or atrogin1, although increased activity of these ligases has been reported in skeletal muscle of $\mathrm{db} / \mathrm{db}$ mice [27]. The reasons for these inconsistencies are not clear at the present time, but may relate to differences in insulin resistance, extent of obesity, and the duration and severity of diabetes seen in mice. Regardless, a dual role of CHIP has been documented such as interaction with HSP70, a family of proteins that rescue damaged proteins, prevent stress-dependent apoptosis in heart, and improve heart function in failing ischemic hearts $[17,28]$. In transgenic mice lacking the CHIP gene, protein expression of HSP70 in cardiac tissue is reduced following ischemia and ischemic injury is enhanced [17]. Our results showing the low protein expression of HSP70 are consistent with the changes occurring in $\mathrm{db} / \mathrm{db}$ hearts. Hearts were studied at 14 weeks when apoptosis is present, left ventricular function is depressed, and sensitivity to ischemia is increased $[22,24]$.

This critical role of GATA4 is supported by the recent observations that GATA4-deleted mice lose the ability for cardiac hypertrophy following pressure overload and exercise stimulation, and overexpression of GATA4 induces cardiac hypertrophy $[13,15]$. Loss of GATA4 expression in the adult mouse heart results in a reduction in left ventricular function [13, 29] and activates proapoptotic factors [15]. The down-regulation of cardiac GATA4 protein is consistent with earlier work [16] and we further extend this observation in the $\mathrm{db} / \mathrm{db}$ heart by demonstrating reduced expression of ANP, BNP, and $\alpha$-MHC. The direct mechanisms leading to reduced expression of these genes are unclear although the consequences on heart structure and function can be substantiated. A reduction in ANP and BNP can alter cardiac structure through it is lack of antihypertrophic and antifibrotic properties in cardiomyocytes, and by inhibition of DNA and collagen synthesis in cardiac fibroblasts [30]. A deficiency in these peptides can also impair diuresis, natriuresis, vasodilation, and inhibit lipolysis [31, 32]. Indeed, 


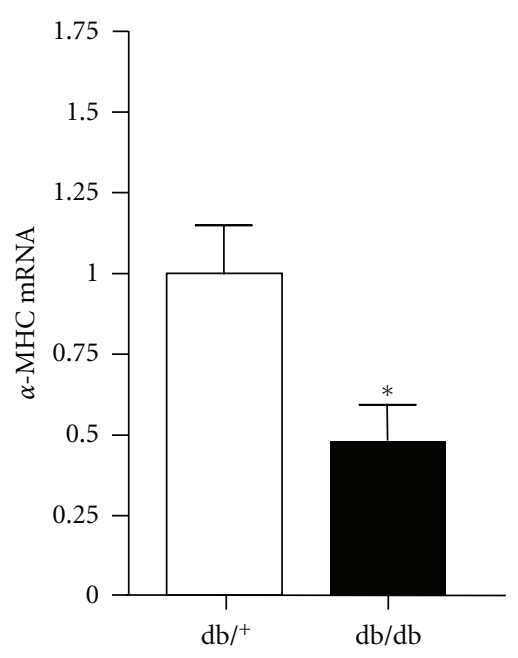

(a)

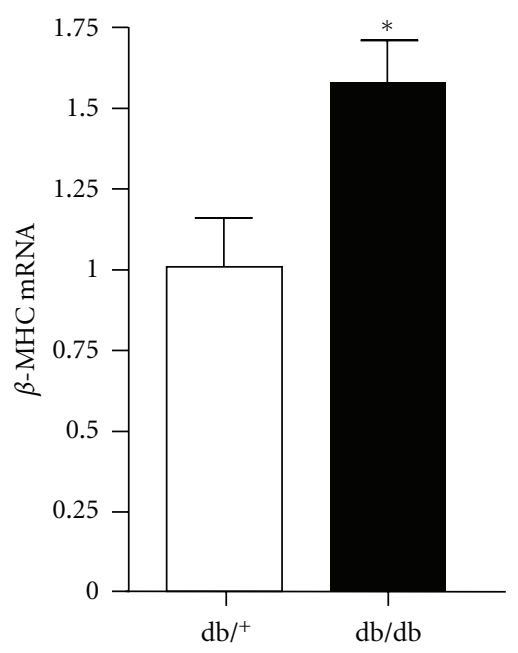

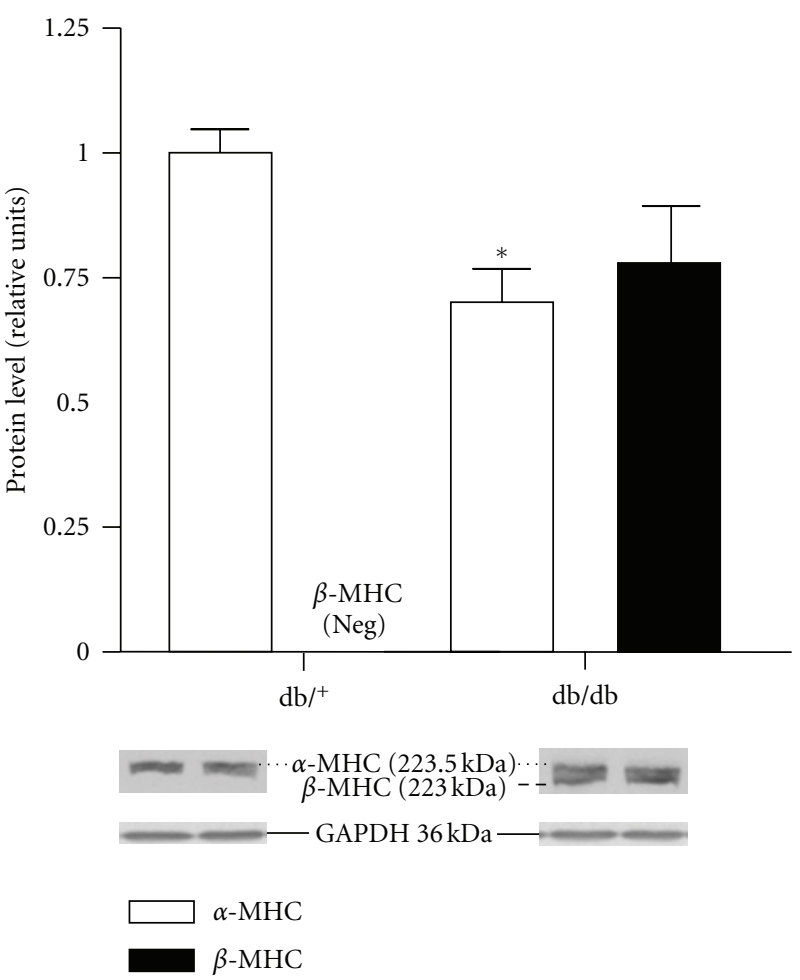

(c)

(b)

Figure 5: Cardiac $\alpha$-MHC mRNA expression (a) $\beta$-MHC mRNA expression (b), and protein expression (c) in control and db/db mice. Protein expression of $\beta$-MHC was not detected in control hearts, whereas in $\mathrm{db} / \mathrm{db}$ hearts, $\beta$-MHC expression was elevated. Values are expressed as mean \pm SEM obtained from 2 separate experiments each performed with 5 hearts. $\mathrm{db} /{ }^{+}$, control mice; $\mathrm{db} / \mathrm{db}$, diabetic mice. $* P<0.05$.

both natriuretic peptides are vasodilators and suppress vasoconstrictors such as the renin-angiotensin-aldosterone and sympathetic nervous systems, vasopressin, and endothelin. The increase in systolic pressure observed in diabetic mice would be consistent with low natriuretic peptide status in these mice. In obese patients, recent reports indicate that plasma ANP and BNP levels are reduced which can explain the increased sodium retention and volume expansion in obese patients, and also contribute to the development of heart failure in obesity [33-35]. The lower levels of BNP in diabetes are of relevance especially given recent evidence that transgenic mice that overexpress BNP are lean and resistant to diet-induced obesity, possibly due to increased lipolysis and fat oxidation in adipose cells as well as an upregulation of mitochondrial biogenesis in muscles [36]. It is likely that the presence of a natriuretic peptide deficit may compound the metabolic changes like intramyocardial accumulation of triglycerides and extracellular deposition of excess collagen followed by activation of several signaling pathways [37, 38]. These events can stimulate the myosin isoform switching as reported in this study.

In humans and rodents, the relative expression of $\alpha$ and $\beta$-MHC isoforms in the heart is controlled by several factors, including the developmental and hormonal milieu, and physiological and pathological states [25, 39-42]. In the failing mouse heart and in models of pressure-induced hypertrophy, a shift from the normally predominant $\alpha$-MHC toward $\beta$-MHC, the major isoform in contractile function and marker of hypertrophy, is observed $[5,25,43]$. In our study, hearts from diabetic mice exhibited a $\sim 50 \%$ decrease 


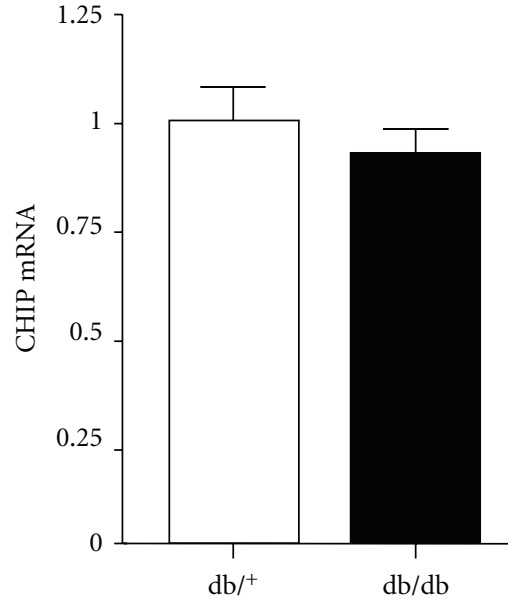

(a)

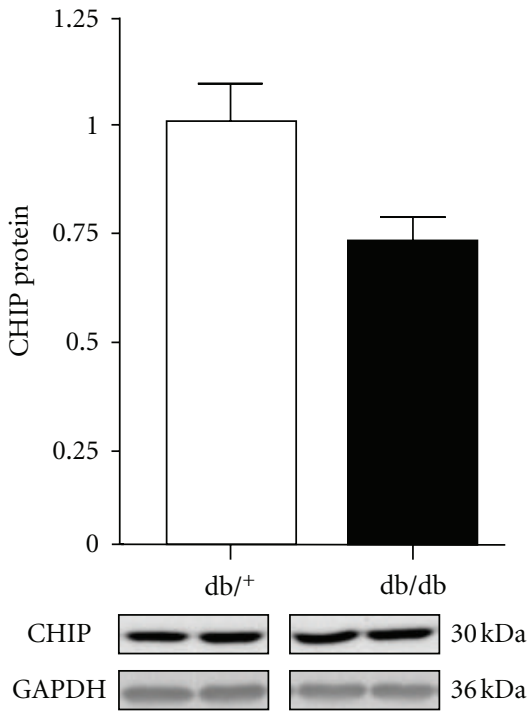

(b)

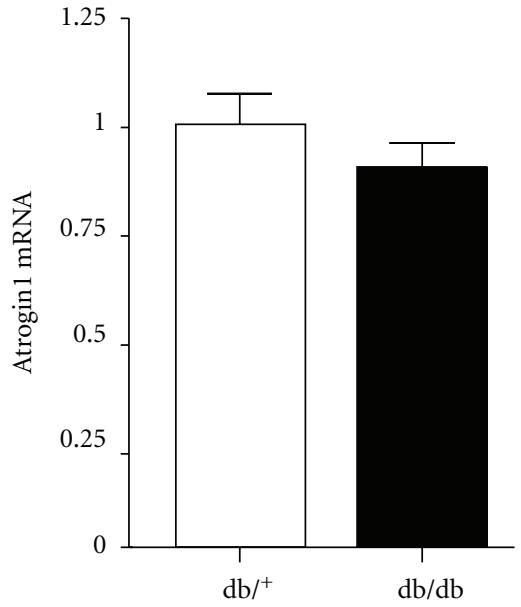

(c)

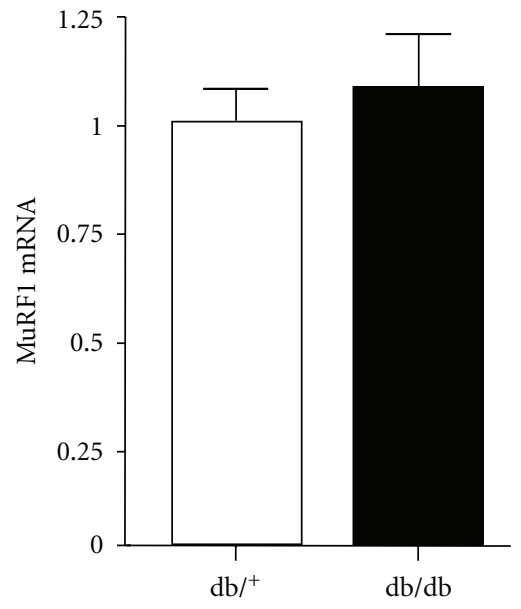

(d)

Figure 6: Cardiac CHIP mRNA and protein expression (a, b), atrogin1 mRNA expression (c), and MuRF1 mRNA expression (d) in control and $\mathrm{db} / \mathrm{db}$ mice. Values are expressed as mean \pm SEM obtained from 2 separate experiments each performed with 5 hearts. $\mathrm{db} /{ }^{+}$, control mice; $\mathrm{db} / \mathrm{db}$, diabetic mice.

in the expression of $\alpha$-MHC and a $\sim 60 \%$ increase in $\beta$-MHC expression. Our data are consistent with the results from an earlier report examining the role of chronic diabetes on $\beta$ MHC expression using the chemically induced diabetic rat [44]. However, increased expression of $\beta$-MHC is generally associated with hypertrophy of the heart, which was not the case in $\mathrm{db} / \mathrm{db}$ mice. Slightly lower heart weights were observed and the heart-weight-to-body-weight ratio was markedly lower in $\mathrm{db} / \mathrm{db}$ mice. However, in a recent study, we and others have demonstrated that hearts from 16-weekold $\mathrm{db} / \mathrm{db}$ were atrophied as a result of increased apoptosis $[23,24]$. The decrease in the hypertrophy marker NAB1 would be consistent with the progression of atrophy of the heart in this model. Ubiquitination within the heart can also account for the atrophy in view of recent evidence linking atrophy of tissues in the $\mathrm{db} / \mathrm{db}$ mouse with insulin resistance and excess glucocorticoid synthesis, conditions known to stimulate atrogin1 and MuRF1 production [27, 45-48]. Interestingly, the hypertension observed in $\mathrm{db} / \mathrm{db}$ mice is not associated with cardiac hypertrophy, suggesting that the increase in systolic pressure may be due to the secondary effects of a low natriuretic peptide status in the $\mathrm{db} / \mathrm{db}$ mouse.

In conclusion, we show that the GATA4-related regulatory downstream transcripts ANP, BNP, and $\alpha$-MHC are reduced in hearts from $\mathrm{db} / \mathrm{db}$ mice. This reduction in GATA4 levels was not associated with any increase in the E3-ubiquitin proteosome ligases. However, cardiac levels of the CHIP cochaperone HSP70 levels were decreased in hearts from $\mathrm{db} / \mathrm{db}$ mice. Together, our results suggest that the downregulation of the GATA4 and associated proteins could in part explain the development of cardiomyopathy in diabetes. 


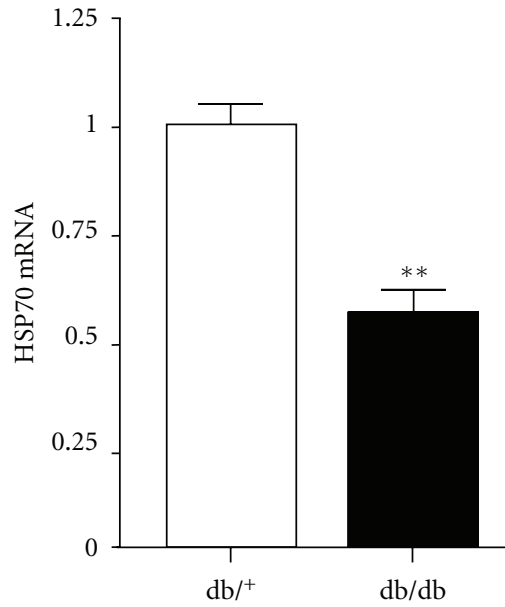

(a)

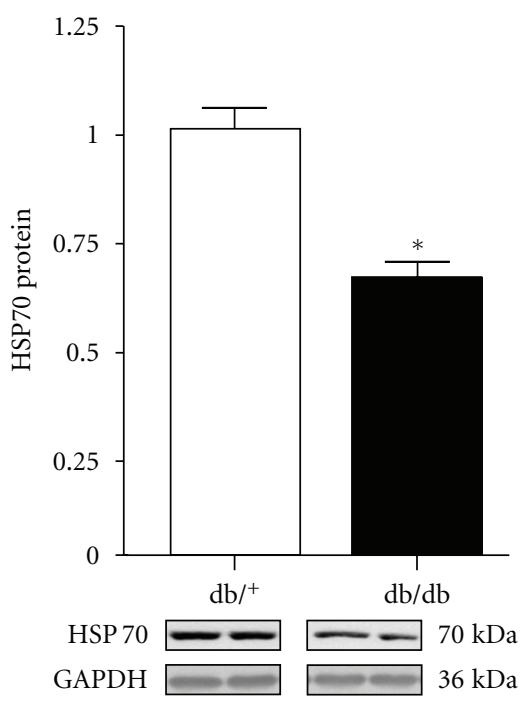

(b)

Figure 7: Cardiac HSP70 mRNA and protein expression in control and db/db mice. Values are expressed as mean \pm SEM obtained from 2 separate experiments each performed with 5 hearts. $\mathrm{db} /{ }^{+}$, control mice; $\mathrm{db} / \mathrm{db}$, diabetic mice. ${ }^{*} P<0.05,{ }^{* *} P<0.01$.

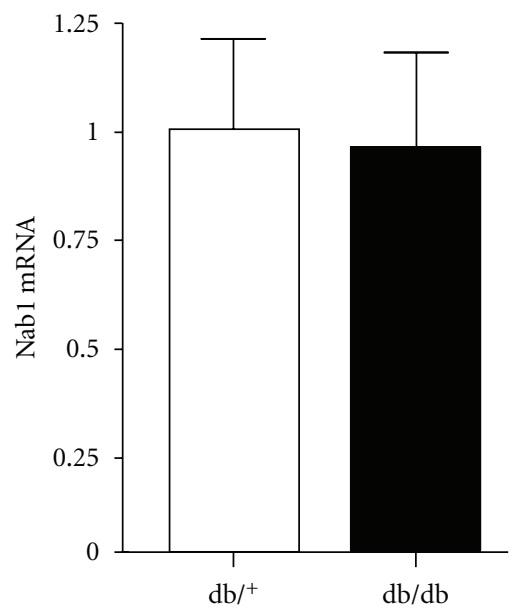

(a)

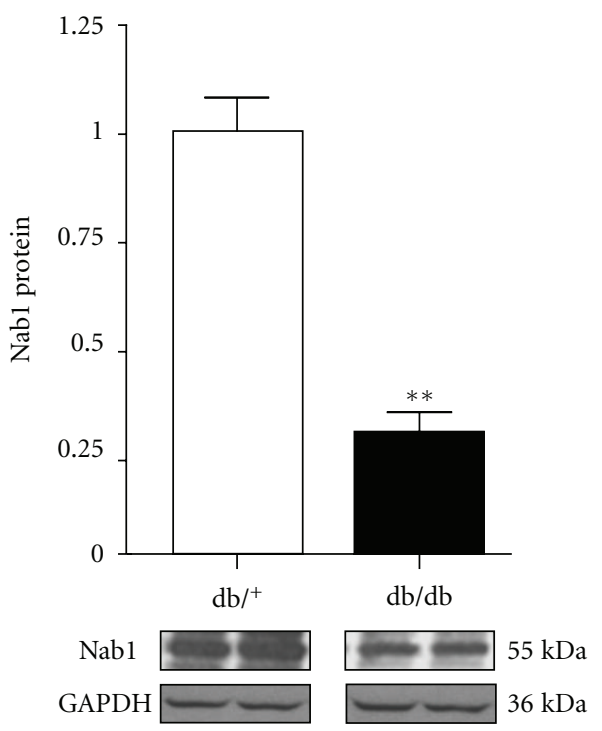

(b)

FIgURE 8: Cardiac Nab-1 mRNA and protein expression in control and db/db mice. Values are expressed as mean \pm SEM obtained from 2 separate experiments each performed with 5 hearts. $\mathrm{db} /{ }^{+}$, control mice; $\mathrm{db} / \mathrm{db}$, diabetic mice. ${ }^{* *} P<0.01$.

\section{Conflict of Interests}

The authors have no financial interests or other conflicts of interest relevant to the content of this study.

\section{Acknowledgments}

This page was supported by the Canadian Institute of Health Research (CIHR, MOP-53217, NET Program) and the Canadian Heart and Stroke Foundation (CHSF, NET Program) as grants to J.Gutkowska and M.Jankowski, and by the Office of Research and Sponsored Programs of Midwestern University and the Diabetes Action and Research Education Foundation to T. L. Broderick.

\section{References}

[1] W. B. Kannel and D. L. McGee, "Diabetes and cardiovascular risk factors: the Framingham study," Circulation, vol. 59, no. 1, pp. 8-13, 1979.

[2] D. L. Dries, N. K. Sweitzer, M. H. Drazner, L. W. Stevenson, and B. J. Gersh, "Prognostic impact of diabetes mellitus 
in patients with heart failure according to the etiology of left ventricular systolic dysfunction," Journal of the American College of Cardiology, vol. 38, no. 2, pp. 421-428, 2001.

[3] B. M. Fisher, G. Gillen, G. B. M. Lindop, H. J. Dargie, and B. M. Frier, "Cardiac function and coronary arteriography in asymptomatic type 1 (insulin-dependent) diabetic patients: evidence for a specific diabetic heart disease," Diabetologia, vol. 29, no. 10, pp. 706-712, 1986.

[4] R. D. Abbott, R. P. Donahue, W. B. Kannel, and P. W. F. Wilson, "The impact of diabetes on survival following myocardial infarction in men vs women. The Framingham Study," Journal of the American Medical Association, vol. 260, no. 23, pp. 34563460, 1988.

[5] C. Depre, M. E. Young, J. Ying et al., "Streptozotocin-induced changes in cardiac gene expression in the absence of severe contractile dysfunction," Journal of Molecular and Cellular Cardiology, vol. 32, no. 6, pp. 985-996, 2000.

[6] S. H. Kim, K. W. Park, Y. S. Kim et al., "Effects of acute hyperglycemia on endothelium-dependent vasodilation in patients with diabetes mellitus or impaired glucose metabolism," Endothelium, vol. 10, no. 2, pp. 65-70, 2003.

[7] S. W. Schaffer, M. S. Mozaffari, M. Artman, and G. L. Wilson, "Basis for myocardial mechanical defects associated with noninsulin-dependent diabetes," American Journal of Physiology, vol. 256, no. 1, pp. E25-E30, 1989.

[8] W. C. Stanley, G. D. Lopaschuk, and J. G. McCormack, "Regulation of energy substrate metabolism in the diabetic heart," Cardiovascular Research, vol. 34, no. 1, pp. 25-33, 1997.

[9] J. D. Molkentin, "The zinc finger-containing transcription factors GATA-4, -5 , and -6: ubiquitously expressed regulators of tissue-specific gene expression," Journal of Biological Chemistry, vol. 275, no. 50, pp. 38949-38952, 2000.

[10] S. Pikkarainen, H. Tokola, R. Kerkelä, and H. Ruskoaho, "GATA transcription factors in the developing and adult heart," Cardiovascular Research, vol. 63, no. 2, pp. 196-207, 2004.

[11] E. Bisping, S. Ikeda, S. W. Kong et al., "Gata4 is required for maintenance of postnatal cardiac function and protection from pressure overload-induced heart failure," Proceedings of the National Academy of Sciences of the United States of America, vol. 103, no. 39, pp. 14471-14476, 2006.

[12] Y. Huang, C. D. Wright, S. Kobayashi et al., "GATA4 is a survival factor in adult cardiac myocytes but is not required for $\alpha 1$ A-adrenergic receptor survival signaling," American Journal of Physiology, vol. 295, no. 2, pp. H699-H707, 2008.

[13] Q. Liang, L. J. De Windt, S. A. Witt, T. R. Kimball, B. E. Markham, and J. D. Molkentin, "The transcription factors GATA4 and GATA6 regulate cardiomyocyte hypertrophy in vitro and in vivo," Journal of Biological Chemistry, vol. 276, no. 32, pp. 30245-30253, 2001.

[14] Y. J. Suzuki, H. Nagase, R. M. Day, and D. K. Das, "GATA-4 regulation of myocardial survival in the preconditioned heart," Journal of Molecular and Cellular Cardiology, vol. 37, no. 6, pp. 1195-1203, 2004.

[15] T. Oka, M. Maillet, A. J. Watt et al., "Cardiac-specific deletion of gata4 reveals its requirement for hypertrophy, compensation, and myocyte viability," Circulation Research, vol. 98, no. 6, pp. 837-845, 2006.

[16] S. Kobayashi, K. Mao, H. Zheng et al., "Diminished GATA4 protein levels contribute to hyperglycemia-induced cardiomyocyte injury," Journal of Biological Chemistry, vol. 282, no. 30, pp. 21945-21952, 2007.

[17] C. Zhang, Z. Xu, X. R. He, L. H. Michael, and C. Patterson, "CHIP, a cochaperone/ubiquitin ligase that regulates protein quality control, is required for maximal cardioprotection after myocardial infarction in mice," American Journal of Physiology, vol. 288, no. 6, pp. H2836-H2842, 2005.

[18] M. Jankowski, F. Hajjar, S. Al Kawas et al., "Rat heart: a site of oxytocin production and action," Proceedings of the National Academy of Sciences of the United States of America, vol. 95, no. 24, pp. 14558-14563, 1998.

[19] E. S. Lee, K. O. Uhm, Y. M. Lee, J. Kwon, S. H. Park, and K. H. Soo, "Oxytocin stimulates glucose uptake in skeletal muscle cells through the calcium-CaMKK-AMPK pathway," Regulatory Peptides, vol. 151, no. 1-3, pp. 71-74, 2008.

[20] M. Florian, M. Jankowski, and J. Gutkowska, "Oxytocin increases glucose uptake in neonatal rat cardiomyocytes," Endocrinology, vol. 151, no. 2, pp. 482-491, 2010.

[21] S. Uchida, S. Fuke, and T. Tsukahara, "Upregulations of Gata4 and oxytocin receptor are important in cardiomyocyte differentiation processes of P19CL6 cells," Journal of Cellular Biochemistry, vol. 100, no. 3, pp. 629-641, 2007.

[22] E. Aasum, A. D. Hafstad, D. L. Severson, and T. S. Larsen, "Agedependent changes in metabolism, contractile function, and ischemic sensitivity in hearts from $\mathrm{db} / \mathrm{db}$ mice," Diabetes, vol. 52, no. 2, pp. 434-441, 2003.

[23] L. A. Barouch, D. Gao, L. Chen et al., "Cardiac myocyte apoptosis is associated with increased DNA damage and decreased survival in murine models of obesity," Circulation Research, vol. 98, no. 1, pp. 119-124, 2006.

[24] J. Gutkowska, T. L. Broderick, D. Bogdan, D. Wang, J. M. Lavoie, and M. Jankowski, "Downregulation of oxytocin and natriuretic peptides in diabetes: possible implications in cardiomyopathy," Journal of Physiology, vol. 587, no. 19, pp. 4725-4736, 2009.

[25] J. J. Mercadier, A. M. Lompre, C. Wisnewsky et al., "Myosin isoenzyme changes in several models of rat cardiac hypertrophy," Circulation Research, vol. 49, pp. 525-532, 1981.

[26] S. W. Lee, G. Dai, Z. Hu, X. Wang, J. Du, and W. E. Mitch, "Regulation of muscle protein degradation: coordinated control of apoptotic and ubiquitin-proteasome systems by phosphatidylinositol 3 kinase," Journal of the American Society of Nephrology, vol. 15, no. 6, pp. 1537-1545, 2004.

[27] X. Wang, Z. Hu, J. Hu, J. Du, and W. E. Mitch, "Insulin resistance accelerates muscle protein degradation: activation of the ubiquitin-proteasome pathway by defects in muscle cell signaling," Endocrinology, vol. 147, no. 9, pp. 4160-4168, 2006.

[28] R. W. Currie and M. Karmazyn, "Improved post-ischemic ventricular recovery in the absence of changes in energy metabolism in working rat hearts following heat-shock," Journal of Molecular and Cellular Cardiology, vol. 22, no. 6, pp. 631-636, 1990.

[29] F. Charron, G. Tsimiklis, M. Arcand et al., "Tissue-specific GATA factors are transcriptional effectors of the small GTPase RhoA," Genes and Development, vol. 15, no. 20, pp. 2702-2719, 2001.

[30] T. Tokudome, T. Horio, T. Soeki et al., "Inhibitory effect of Ctype natriuretic peptide (CNP) on cultured cardiac myocyte hypertrophy: interference between CNP and endothelin-1 signaling pathways," Endocrinology, vol. 145, no. 5, pp. 21312140, 2004.

[31] R. L. Woods, "Cardioprotective functions of atrial natriuretic peptide and B-type natriuretic peptide: a brief review," Clinical and Experimental Pharmacology and Physiology, vol. 31, no. 11, pp. 791-794, 2004.

[32] A. L. Birkenfeld, P. Budziarek, M. Boschmann et al., "Atrial natriuretic peptide induces postprandial lipid oxidation in humans," Diabetes, vol. 57, no. 12, pp. 3199-3204, 2008. 
[33] H. Kälsch, T. Neumann, and R. Erbel, "Less increase of BNP and NT-proBNP levels in obese patient with decompensated heart failure. Interpretation of natriuretic peptides in obesity," International Journal of Cardiology, vol. 133, no. 1, pp. e22e24, 2009.

[34] J. A. Taylor, R. H. Christenson, K. Rao, M. Jorge, and S. S. Gottlieb, "B-Type natriuretic peptide and N-terminal pro B-type natriuretic peptide are depressed in obesity despite higher left ventricular end diastolic pressures," American Heart Journal, vol. 152, no. 6, pp. 1071-1076, 2006.

[35] M. R. Mehra, P. A. Uber, M. H. Park et al., "Obesity and suppressed B-type natriuretic peptide levels in heart failure," Journal of the American College of Cardiology, vol. 43, no. 9, pp. 1590-1595, 2004.

[36] K. Miyashita, H. Itoh, H. Tsujimoto et al., "Natriuretic peptides/cGMP/cGMP-dependent protein kinase cascades promote muscle mitochondrial biogenesis and prevent obesity," Diabetes, vol. 58, no. 12, pp. 2880-2892, 2009.

[37] S. Boudina and E. D. Abel, "Diabetic cardiomyopathy revisited," Circulation, vol. 115, no. 25, pp. 3213-3223, 2007.

[38] A. Guha, R. Harmancey, and H. Taegtmeyer, "Nonischemic heart failure in diabetes mellitus," Current Opinion in Cardiology, vol. 23, no. 3, pp. 241-248, 2008.

[39] D. L. Allen and L. A. Leinwand, "Postnatal myosin heavy chain isoform expression in normal mice and mice null for IIb or IId myosin heavy chains," Developmental Biology, vol. 229, no. 2, pp. 383-395, 2001.

[40] W. H. Dillmann, "Hormonal influences on cardiac myosin ATPase activity and myosin isoenzyme distribution," Molecular and Cellular Endocrinology, vol. 34, no. 3, pp. 169-181, 1984.

[41] D. P. Fitzsimons, P. W. Bodell, R. E. Herrick, and K. M. Baldwin, "Left ventricular functional capacity in the endurancetrained rodent," Journal of Applied Physiology, vol. 69, no. 1, pp. 305-312, 1990.

[42] M. Krenz and J. Robbins, "Impact of beta-myosin heavy chain expression on cardiac function during stress," Journal of the American College of Cardiology, vol. 44, no. 12, pp. 2390-2397, 2004.

[43] J. Giger, A. X. Qin, P. W. Bodell, K. M. Baldwin, and F. Haddad, "Activity of the $\beta$-myosin heavy chain antisense promoter responds to diabetes and hypothyroidism," American Journal of Physiology, vol. 292, no. 6, pp. H3065-H3071, 2007.

[44] D. J. Paulson, M. Gupta, R. Zak, and J. Zhao, "Effects of exercise training and diabetes on cardiac myosin heavy chain composition," Molecular and Cellular Biochemistry, vol. 117, no. 2, pp. 175-179, 1992.

[45] B. A. Clarke, D. Drujan, M. S. Willis et al., "The E3 ligase MuRF1 degrades myosin heavy chain protein in dexamethasone-treated skeletal muscle," Cell Metabolism, vol. 6, no. 5, pp. 376-385, 2007.

[46] Z. Liu, W. R. Miers, L. Wei, and E. J. Barrett, "The ubiquitinproteasome proteolytic pathway in heart vs skeletal muscle: effects of acute diabetes," Biochemical and Biophysical Research Communications, vol. 276, no. 3, pp. 1255-1260, 2000.

[47] D. L. Coleman and D. L. Burkart, "Plasma corticosterone concentrations in diabetic ( $\mathrm{db}$ ) mice," Diabetologia, vol. 13, no. 1, pp. 25-26, 1977.

[48] M. Sandri, C. Sandri, A. Gilbert et al., "Foxo transcription factors induce the atrophy-related ubiquitin ligase atrogin-1 and cause skeletal muscle atrophy," Cell, vol. 117, no. 3, pp. 399-412, 2004. 


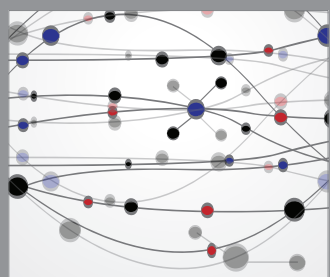

The Scientific World Journal
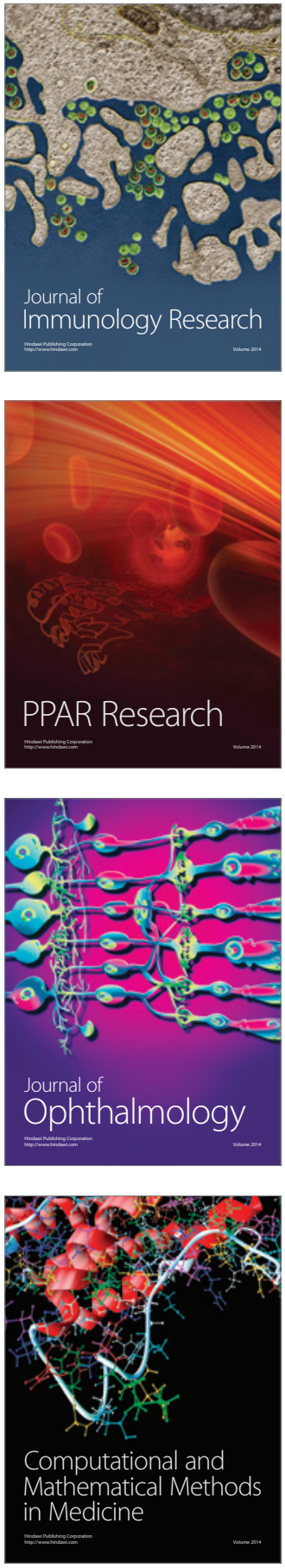

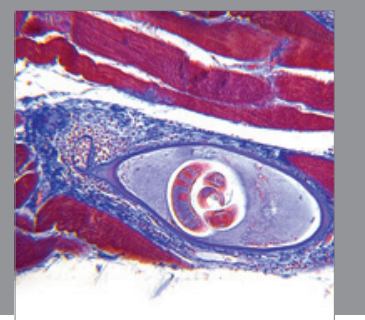

Gastroenterology

Research and Practice
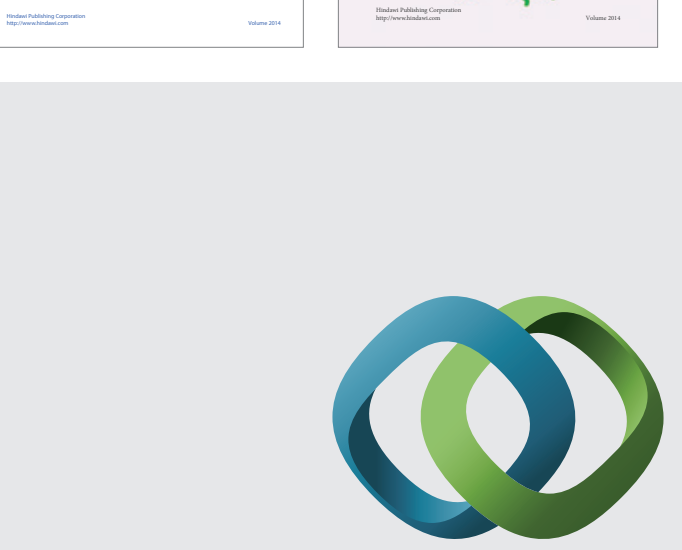

\section{Hindawi}

Submit your manuscripts at

http://www.hindawi.com
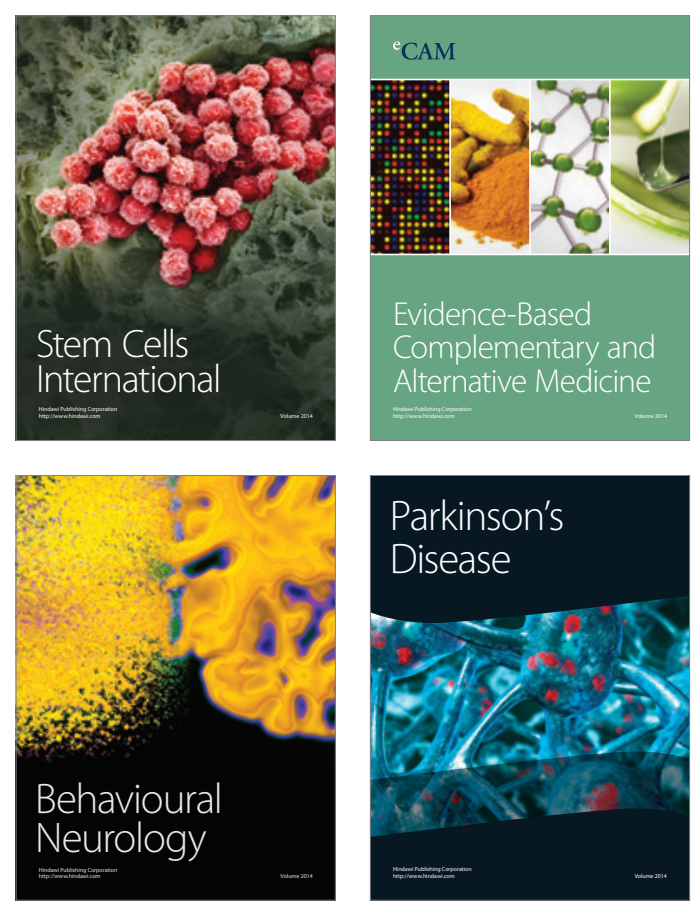

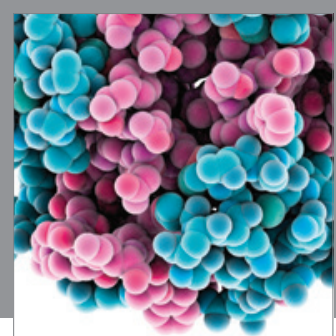

Journal of
Diabetes Research

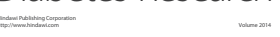

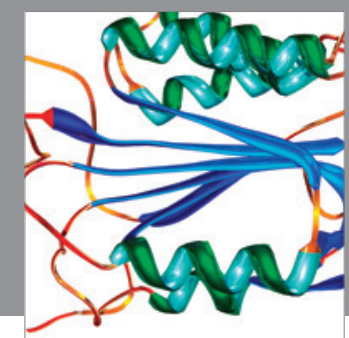

Disease Markers
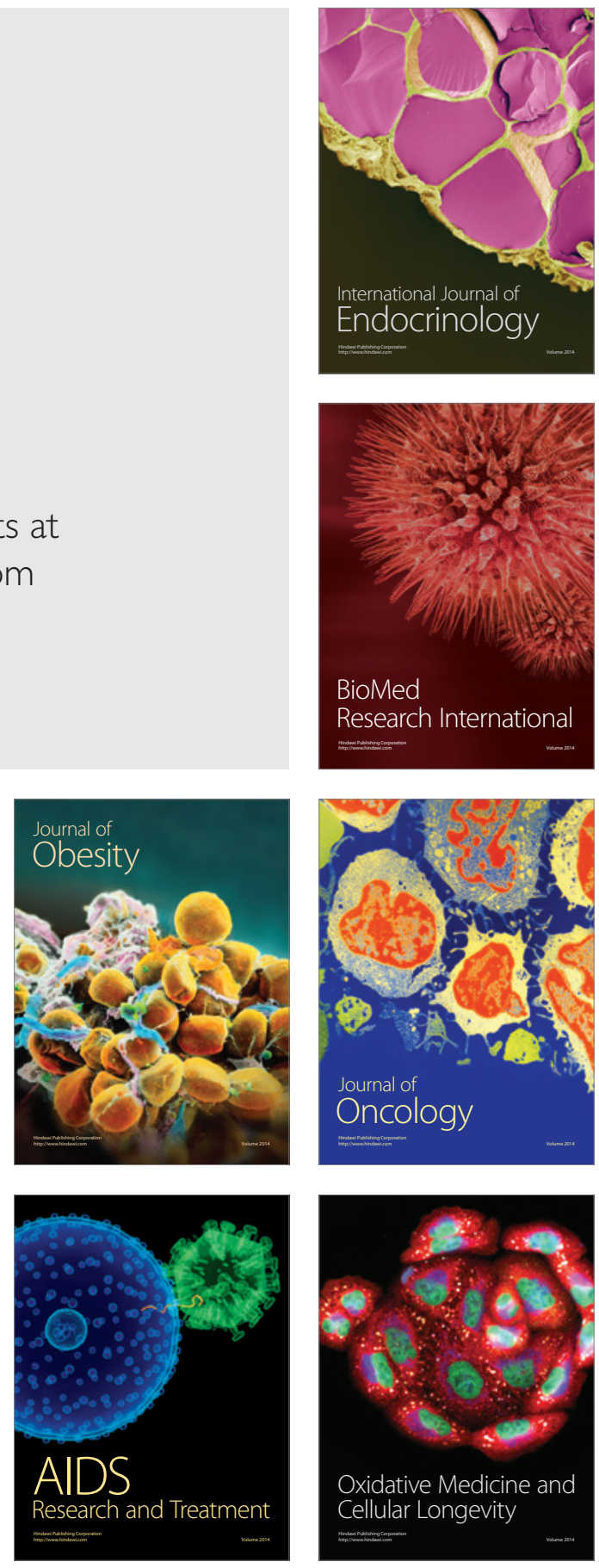